\title{
A FORMAL AUDIT AS CONTINUING MEDICAL EDUCATION: ANAESTHESIA FOR NEUROSURGERY
}

\author{
J.W.R. MCINTYRe AND J.G. PuRdelL-LewIS
}

\begin{abstract}
A brief description of the change from a normative evaluation to a formal audit of anaesthesia for neurosurgery is described. The criteria to be applied and their significance for clinical practise are listed. It is emphasized that these items are not presented as criteria for the standard of anaesthesia practised but as matters deserving debate among anaesthetists participating in a formal audit, particularly where the case load does not permit statistical analysis of patient outcome and only discussion of individual patients or small groups is possible. It is suggested, as it has been by others, that formal audit in a department of anaesthesia can be developed as the form of continuing medical education most closely related to the clinical work of the anaesthetists working within it.
\end{abstract}

Key Words: Continuing Medical Education, formal audit.

DURING THE LAST few years increasing public emphasis has been placed on the duty of physicians to maintain their professional competence. Information sources for continuing medical education have proliferated but the relationship between attendance at them and patient outcome has remained more a matter of likelihood than established fact. Purveyors of education realize that, among other things, to be attractive and useful it must be relevant to the needs of the consumer and be as time effective as possible. What follows here is an account of our experience of audit as a continuing medical educational strategy. The example concerns anaesthesia for neurosurgical procedures.

Our experience of neuroanaesthesia audit began in 1976 when the questions "What are we doing?" and to a lesser extent "How are we doing it?" were asked. To this end the Medical Records Department at the University of Alberta Hospital provided all the charts of neurosurgical "discharges" for the period January to June 1976. These charts were examined by one of the authors (J.G. P-L.) and data were collected as shown in Table I. Data in each category were recorded on Assembler Coding Forms using a ' $0-1$ ' or ' $0-1-2 \ldots$ ' system as appropriate. The information gained was collated and presented at Department of Anaesthesia Rounds.

The normative evaluation in 1977 was limited

J.W.R. McIntyre, F.R.C.P.(C); J.G. PurdellLewis, F.R.C.P.(C): Department of Anaesthesia, University of Alberta, Edmonton, Alberta.

Can. Anaesth. Soc. J., vol. 29, no. 2, March 1982 to selected procedures (Table II) carried out in patient discharges for January 1st to December 31 st. Utilising the experience gained in acquiring the broad overview of our neuroanaesthetic practice in 1976 the anaesthetic management was recorded in greater detail. Additional data included the duration of post-operative ventilation and tracheal intubation, how long the arterial line was retained, and the final outcome.

In 1978 a similar format was used and applied to neurosurgical patients during the period January 1st to December 31st, 1978. The only obvious changes in practise were that the use of preoperative intra-arterial blood pressure measurement during craniotomy for tumours increased from 48 to 67 per cent of cases. The Bain circuit was also used more frequently. Presentation of the findings in the normative evaluations had not been associated with efforts at education and these few changes are almost certainly due to other factors influencing the transfer and application of knowledge such as casual conversation, joumals, and medical meetings.

This educational deficiency of normative evaluations and the stultifying effect of larger numbers of statistics make the concept of a formal audit more attractive, particularly as it relates directly to patient care and the day-to-day work of the audience. A formal audit refers to the establishment of criteria for assessment of practice and the subsequent application of those criteria to clinical practice. In 1979 preparations for a formal audit were made by deciding on 174 
TABLE I

Categories of Data Collected

IN NEUROANAESTHESIA AUDITs 1976-1977-1978

\begin{tabular}{l} 
Sex Duration of Anaesthesia \\
Age Operative Procedure \\
A.S.A. Risk Rating Patient Position During Surgery \\
Monitoring Details \\
Blood pressure: \\
Sphygmomanometer and cuff \\
Intra-arterial line and site \\
Electrocardiograph \\
Arterial blood gases with values \\
Stethoscope: \\
Precordial \\
Oesophageal \\
Precordial Doppler Air Detector \\
Right atrial line \\
Body temperature \\
Intracranial Pressure: \\
Assessment \\
Management \\
Fluid Management: \\
Urinary output \\
Crystalloid infusion \\
Blood loss \\
Blood transfusion \\
Cardiovascular Stability: \\
Blood pressure changes from baseline \\
Heart rate changes from baseline \\
Airway Management: \\
Endotracheal tube type and route of insertion \\
Recorded complications \\
Anaesthesia Management: \\
Induction agents \\
Maintenance agents \\
Muscle relaxants \\
Mode of ventilation \\
Circuit \\
Controlled hypotension and agent used \\
Post-Operative Course: \\
Duration of I.P.P.V. \\
Duration of tracheal intubation \\
Duration of arterial line \\
Outcome (compared to preoperative status) \\
including mortality and cause. \\
\hline
\end{tabular}

twelve criteria to be applied. These were presented for approval to anaesthetists providing anaesthesia for neurosurgery. The first nine of the criteria were to be used for patients anaesthetized in the supine position and all twelve of them for patients in the sitting position. These are summarized in Table III. Details of the criteria and why they were considered important are as follows:

\section{Use of volatile anaesthetic agents}

Was the use of halothane 1.5 per cent or enflurane 2 per cent and concentrations greater
TABLE II

Operative Procedures InCluded FOR AUdit PURPOSES

\begin{tabular}{ll}
\hline \hline Year & Procedures \\
\hline 1976 & $\begin{array}{l}\text { All operative procedures carried out } \\
\text { by Neurosurgeons. } \\
\text { Craniotomy for intracranial mass, } \\
\text { including tumour (does not include } \\
\text { acute trauma). } \\
\text { Craniotomy for cerebral aneurysm } \\
\text { and arterio-venous malformation. } \\
\text { Craniotomy for: C.S.F. leak, external } \\
\text { carotid-internal carotid anasto- } \\
\text { mosis, carotid cavernous fistula, } \\
\text { and brain resection for epilepsy. } \\
\text { Trans-sphenoidal hypophysectomy. } \\
\text { Posterior fossa and cervical pro- } \\
\text { cedures carried out in the sitting } \\
\text { position. }\end{array}$ \\
\hline
\end{tabular}

TABLE III

Summary of Criteria for Formal Audit, 1979

Nos. 1-9 applied to patients operated on in the supine or lateral position and Nos. 1-12 to patients in the sitting position.

1. Use of volatile anaesthetic agents

2. Ventilation

3. Use of muscle relaxants

4. Placement of E.C.G. leads and monitor

5. Use of intra-arterial blood pressure measurement

6. Intravenous fluid administration

7. Fluid loss

8. Measurement of body temperature

9. Measurement of arterial blood gases

10. Placement of right atrial catheter

11. Placement of precordjal Doppler ultrasonic bubble detector

12. Placement of oesophageal stethoscope

than those for periods of time longer than five minutes avoided?

Significance. The influence of inhalational agents on autoregulation of cerebral blood flow ${ }^{1}$ and the ensuing changes in intracranial pressure that are produced; ${ }^{2}$ inhalational agents are also reported to have a toxic effect on cerebral metabolism. ${ }^{3.4}$

\section{Parameters of ventilation}

Were either details of fresh gas flow, anaesthesia circuit, minute volume and ventilation pressures, or two or more blood gas measurements during the first hour of anaesthesia recorded?

Significance. Pre-existing cardiac and pulmonary disease together with changes which 
can occur during anaesthesia and operation can profoundly influence oxygen and carbon dioxide homeostasis and the brain. Deviations of oxygen and carbon dioxide tensions from normal levels effect cerebral blood flow, ${ }^{5.6}$ intracranial pressure ${ }^{7}$ and cerebral metabolism. ${ }^{8}$

\section{Use of muscle relaxants}

Was a neuromuscular blocking drug employed for the duration of the case?

Significance. Neuromuscular blockade facilitates ventilation using minimal airway pressures and ensures a patient cannot buck during the operation.

\section{Use of an electrocardiograph}

Was the electrocardiograph monitor employed during the procedure?

Significance. Brain tumours and other central nervous system lesions are associated with various abnormalities of cardiac rhythm which maybeaggravated by surgicalmanipulations. If these arrhythmias are not immediately recognized and corrective action taken cerebral ischaemia is likely to occur. ${ }^{9-12}$

5. Use of intra-arterial blood pressure measurement

Was an arterial catheter present and used for systemic blood pressure measurement?

Significance. Systemic blood pressure is a vital factor of cerebral blood flow and during major neurosurgical procedures important fluctuations may be rapid and frequent. Beat to beat information facilitates early recognition of problems and therapeutic intervention. The error of measurement during intra-arterial pressure monitoring is less than that with a sphygmomanometer and so enables a controlled hypotensive technique to be pursued more accurately. ${ }^{9,11,12}$

\section{Intravenous fluid administration}

Were there sequential numerical records of fluids and electrolytes administered throughout the case?

Significance. One of the factors affecting cardiovascular homeostasis is circulating blood volume and this is influenced by fluid and electrolyte administration. The administration of dextrose 5 per cent in water is potentially dangerous as it can lead to the development of cerebral oedema ${ }^{13}$ and electrolytes influence brain homeostasis.

\section{Fluid loss}

Were there sequential numerical records of blood loss and urinary output?

Significance. Measured or estimated blood loss is an important guide to blood replacement. Urine output is a useful indication of renal function.

\section{Body temperature}

Was body temperature measured sequentially during the procedure?

Significance. Changes in body temperature affect the body in a complex manner. $A$ fall in brain temperature produces a linear fall in cerebral metabolism and thus function. A one degree centigrade fall in brain temperature reduces cerebral metabolism by five per cent. $^{14}$

\section{Arterial blood gas measurement}

Were a minimum of two measurements done during the operation?

Significance. The acid base and blood gas status has a major impact on cerebral blood flow, intracranial pressure, and cerebral perfusion pressure.

\section{Right atrial catheterisation}

Was a right atrial catheter in position?

Significance. Venous air embolism is a potential hazard when the site of operation is above the heart. Patients undergoing neurosurgical procedures in the sitting position are particularly at risk and the use of a right atrial catheter is valuable for diagnosis, management and air aspiration. ${ }^{15,16}$

\section{Doppler ultrasonic bubble detector}

Was a Doppler ultrasonic bubble detector employed during the procedure?

Significance. Early detection, treatment and control of venous air embolism is essential in patients undergoing neurosurgical procedures in the sitting position. ${ }^{15,17}$

\section{Oesophageal stethoscope}

Was an oesophageal stethoscope in situ during the operation?

Significance. Air embolism in the sitting neurosurgical patient can be a life threatening complication, and the use of an oesphageal stethoscope to detect the sounds of cardiac air embolism as a back-up to the precordial Doppler ultrasonic bubble detector is important. ${ }^{15,18}$ 
These criteria were used for a six month formal audit of procedures done between July 1 st and December 31st, 1980. One hundred and one records were examined and classified according to surgical procedure and posture during operation (Table IV). The anaesthetist was designated by number. As mentioned earlier, nine criteria were applied to patients in the supine posture and all twelve to patients operated on in the sitting position. Collective findings based on all anaesthetics appear in Table $V$. The number of times each of the audited criteria was satisfied in each surgical group is compared with the maximum possible score and the result is expressed as a percentage. Nineteen anaesthetists participated in the audit and the individual fulfillment of the audited criteria is described in a similar fashion (Table VI). It is clear that, based on information available in the anaesthetic records, there was considerable variation in the way different anaesthetists administered the anaesthetics and considerable variation in the case load of different anaesthetists.

In discussing our experiences with this formal audit, reference must be made to the time, and therefore expense, of data collection and analysis. This was formidable because much of the data from the anaesthetic records had to be assembled by an anaesthetist. The effort involved could be reduced by computer based data entry and storage from the operating room. Altematively an anaesthetic record designed with the formal audit in mind might facilitate recording by the anaesthetist and assembly of the data later by lay personnel. Perhaps it is time that the flow sheet type of record prevalent in intensive care units should be adopted for some purposes in the operating room. Difficulties with

TABLE IV

Operative Procedures Included FOR AUDIT PURPOSES JULY-DECEMBER 1980

Craniotomy for intracranial mass, including tumour (does not include acute trauma).

Craniotomy for cerebral aneurysm and arteriovenous malformation.

Posterior fossa and cervical procedures carried out in the sitting position.

Varying pathology:

includes craniotomy for C.S.F. leak, externalinternal carotid anastomosis, carotid cavernous fistula, and brain resection for epilepsy; transsphenoidal hypophysectomy, cranio synostosis; and prolonged, major procedures in the prone position. data assembly just alluded to are a reminder that the quality of records is not necessarily an accurate assessment of the medical care provided that particular patient. ${ }^{19}$ The anaesthetist does not necessarily record all that he or she has done. However, maintenance of adequate records is a requirement of regulatory bodies and, in that a record is initiated at all, it is reasonable to assume that it includes a fairly comprehensive account of what was done during the course of the anaesthetic. Thus the audit findings are assumed to represent faithfully what was or was not done and there was considerable variation in patient management.

One objective of an audit is to demonstrate differences in patient outcome with reference to varying degrees of criteria fulfilment. This objective could not be satisfied statistically because of the numbers of patients in the different audit groups. In the audit planning stage the introduction of critical incident recording during anaesthesia was considered but implementation of such a thing was postponed. Thus we cannot relate our audit findings to patient outcome and are left with only the belief that if these criteria of care are met then a patient is more likely to have a beneficial outcome. The results of the audit should be a prelude to change and it appears that ventilation, blood-gas measurement, temperature measurement, the use of the oesophageal stethoscope, and the use of volatile anaesthetic agents merit particular attention. Volatile agents are of particular interest in the context of this audit because they draw attention to the need for re-evaluating audit criteria and then rigour in application as well as discussion of new criteria. The inspired concentration of a volatile drug cannot necessarily be predicted accurately even if the vaporizer setting and fresh gas flow are known. New criteria to be proposed are measurements of electrolytes and osmolality. Only future audits will show whether a change presumably beneficial to patients has occurred. However, it is encouraging that an in-house request has been made for the preparation of Guidelines and a Checklist for Neurosurgical Anaesthesia. We are indeed grateful for the numerous publications by specialists in this area that can be summarized for such a purpose.

In conclusion, the Canadian Council on Hospital Accreditation introduced Standard V Professional Care Evaluation in $1977 .^{23}$ This states that ..."the medical staff shall ensure the quality of professional care provided to patients in the hospital by a continual review and evalua- 


\section{TABLE V}

\begin{tabular}{|c|c|c|c|c|c|c|c|c|c|c|}
\hline \multirow[b]{4}{*}{ Number of cases } & \multirow{2}{*}{\multicolumn{4}{|c|}{ Supine Position }} & \multirow{3}{*}{\multicolumn{2}{|c|}{$\begin{array}{c}\begin{array}{c}\text { Position } \\
\text { Sitting }\end{array} \\
\begin{array}{c}\text { Posterior } \\
\text { Fossa }\end{array} \\
\text { \& Cervical } \\
\text { Pathology }\end{array}$}} & \multirow{3}{*}{\multicolumn{2}{|c|}{$\begin{array}{c}\begin{array}{c}\text { Position } \\
\text { Supine } \\
\text { or Prone }\end{array} \\
\begin{array}{c}\text { Varying } \\
\text { Pathology }\end{array}\end{array}$}} & \multirow{3}{*}{\multicolumn{2}{|c|}{ Total }} \\
\hline & & & & & & & & & & \\
\hline & \multicolumn{2}{|c|}{$\begin{array}{l}\text { Intracranial } \\
\text { Tumour }\end{array}$} & \multicolumn{2}{|c|}{$\begin{array}{l}\text { Aneurysm } \\
\& \text { A.V.M. }\end{array}$} & & & & & & \\
\hline & 41 & $\%$ & 30 & $\%$ & 8 & $\%$ & 22 & $\%$ & 101 & $\%$ \\
\hline Volatile agents & $31 / 39$ & 79 & $18 / 28$ & 64 & $8 / 8$ & 100 & $13 / 18$ & 72 & $70 / 93$ & 75 \\
\hline Ventilation & 32 & 78 & 26 & 87 & 6 & 75 & 15 & 68 & 79 & 78 \\
\hline Muscle relaxants & 41 & 100 & 30 & 100 & 8 & 100 & 20 & 91 & 99 & 98 \\
\hline E.C.G. & 40 & 98 & 30 & 100 & 7 & 87 & 22 & 100 & 99 & 98 \\
\hline Arterial line & 40 & 98 & 29 & 97 & 6 & 75 & 17 & 77 & 92 & 91 \\
\hline Blood gases $3(+)$ & 24 & 59 & 24 . & 80 & 4 & 50 & 5 & 23 & 57 & 56 \\
\hline Fluid input & 37 & 90 & 29 & 97 & 5 & 62 & 16 & 73 & 87 & 86 \\
\hline Fluid output & 36 & 88 & 29 & 97 & 5 & 62 & 15 & 68 & 85 & 84 \\
\hline Temperature & 14 & 34 & 9 & 30 & 2 & 25 & 3 & 14 & 28 & 28 \\
\hline Oesoph. steth. & & & & & 3 & 37 & & & $3 / 8$ & 37 \\
\hline Pre-cordial doppler & & & & & 7 & 87 & & & $7 / 8$ & 87 \\
\hline R. atrial catheter & & & & & 6 & 75 & & & $6 / 8$ & 75 \\
\hline
\end{tabular}

Combined data for all anaesthetists. The number of times a criterion was satisfied compared with the maximum number that could be achieved.

TABLE VI

\begin{tabular}{|c|c|c|c|c|c|}
\hline \multicolumn{2}{|c|}{ Supine \& Lateral Position } & \multirow{2}{*}{$\begin{array}{c}\begin{array}{c}\text { Sitting } \\
\text { Position }\end{array} \\
\text { Posterior } \\
\text { Fossa } \\
\text { \& Cervical }\end{array}$} & \multirow{2}{*}{$\begin{array}{c}\begin{array}{c}\text { Supine } \\
\text { or Prone }\end{array} \\
\begin{array}{c}\text { Varying } \\
\text { Pathology }\end{array}\end{array}$} & \multirow[b]{2}{*}{$\begin{array}{l}\text { Total } \\
\text { Score }\end{array}$} & \multirow[b]{2}{*}{$\%$} \\
\hline $\begin{array}{l}\text { Intracranial } \\
\text { Tumour }\end{array}$ & $\begin{array}{l}\text { Aneurysm } \\
\text { \& A.V.M. }\end{array}$ & & & & \\
\hline $11 / 18$ & - & - & $2 / 9$ & $13 / 27$ & 48 \\
\hline $9 / 9$ & $6 / 9$ & $5 / 12$ & $8 / 18$ & $28 / 48$ & 58 \\
\hline $12 / 18$ & - & - & $13 / 18$ & $25 / 36$ & 69 \\
\hline $25 / 36$ & $19 / 27$ & - & $7 / 9$ & $51 / 72$ & 71 \\
\hline $5 / 9$ & $16 / 18$ & - & $18 / 27$ & $39 / 54$ & 72 \\
\hline $7 / 9$ & $8 / 9$ & - & $11 / 18$ & $26 / 36$ & 72 \\
\hline $20 / 27$ & $8 / 9$ & $9 / 12$ & $6 / 9$ & $43 / 57$ & 75 \\
\hline $36 / 45$ & $8 / 9$ & $8 / 12$ & $5 / 9$ & $57 / 75$ & 76 \\
\hline $23 / 27$ & $7 / 9$ & $7 / 12$ & - & $37 / 48$ & 77 \\
\hline $43 / 54$ & $8 / 9$ & - & $12 / 18$ & $63 / 81$ & 78 \\
\hline $8 / 9$ & $6 / 9$ & $11 / 12$ & $6 / 9$ & $31 / 39$ & 79 \\
\hline- & 819 & $9 / 12$ & $7 / 9$ & $24 / 30$ & 80 \\
\hline- & $22 / 27$ & - & - & $22 / 27$ & 81 \\
\hline $23 / 27$ & $16 / 18$ & $19 / 24$ & $13 / 18$ & $71 / 87$ & 82 \\
\hline- & $15 / 18$ & - & - & $15 / 18$ & 83 \\
\hline $16 / 18$ & $15 / 18$ & - & - & $31 / 36$ & 86 \\
\hline $33 / 36$ & $7 / 9$ & - & $15 / 18$ & $55 / 63$ & 87 \\
\hline $9 / 9$ & $16 / 18$ & $8 / 12$ & $9 / 9$ & $42 / 48$ & 87 \\
\hline $18 / 18$ & $42 / 45$ & - & - & $60 / 63$ & 95 \\
\hline
\end{tabular}

Data for each anaesthetist participating in the audit. The number of times a criterion was satisfied compared with the maximum that could be achieved.

tion of the overall patterns of clinical practice of the clinical activities of its individual members, and of the ultimate effectiveness of the patient care rendered."

The formal audit described is a review of our current practice and an evaluation of care in the light of current knowledge. The experience reported here leads us to the following conclusions: (a) change in certain aspects of patient care appear to be necessary; (b) changes in 
record keeping are necessary if data collection is to be delegated effectively to non-medical personnel; (c) the relevance of the findings reported to clinical work stimulates the interest of the anaesthetists involved; (d) a desire to improve patient care is generated; (e) although it is desirable to keep the same criteria for repetitive audit periods provision should be made for the revision of criteria and the adoption of new ones. Hardyment has drawn attention to peer group analysis as a form of medical audit and its role in continuing medical education ${ }^{22}$ and we believe that this can be a worthwhile attempt to maintain and improve the quality of patient care in the light of new knowledge.

\section{ACKNOWLEDGEMENT}

The authors gratefully acknowledge the collaboration of colleagues in the Department of Anaesthesia - Drs. D. Dobson, B. Glauser, R.C. Gregg, F. Haley, H.G. Haynes, L.J. Huston, W.D. Kyle, J.D. McFarland, G.T. Moonie, G.H. Morton, D.R. Preston, H. Reine, M.A. Rensaa and D.H. Wiebe.

\section{REFERENCES}

1. Morita, H Nemoto, EM \& Bleyaert A L. Brain blood flow autoregulation and metabolism during halothane anaesthesia in monkeys. Am. J. Physiol. 233: H671 (1977).

2. Boop, W.C. \& KNIGHT, R. Enflurane anaesthesia and changes in intracranial pressure. J. Neurosurg. 48: 228 (1978).

3. COHEN, P.J. Effect of anesthetics on mitochondrial function. Anesthesiology 39: 153 (1973).

4. MiCHENFELDER, J.D. \& THEYE, R.A. In vivo toxic effects of halothane on canine cerebral metabolic pathways. Am. J. Physiol. 229: 1050 (1975).

5. LASSEN, N.A. Brain extracellular pH: main factor controlling cerebral blood flow. Scand. J. Clin. Lab. Invest. 22: 247 (1968).

6. MCDowall, D.G. Oxygen measurements in blood and tissues. Edited by Payne, J.P., and Hill, D.W. London, Churchill Livingstone, p. 205 (1966).

7. Marrubini, M.B., Rossanda, M. \& TRetola, L. The role of artificial ventilation in the control of brain tension during neurosurgical operations Brit. J. Anaesth. 36: 415 (1964).

8. SIESJo, B.K. The influence of respiratory disturbances on acid-base and energy metabolism of the brain. Intensive Care Med. 3: 245 (1977).

9. SAmuels, S.I. Anaesthesia for supratentorial tumour. Anesthesia and neurosurgery. Edited by Cottrell, J.E., and Turndorf, H. St. Louis, Mosby, p. 150 (1980).

10. WHITBY, J.D. Electrocardiography during posterior fossa operations. Brit. J. Anaesth. 35: 624 (1963).

11. Newfield, P. Anesthesia for post fossa procedures. Anesthesia and neurosurgery. Edited by Cottrell, J.E. and Turndorf, H. St. Louis, Mosby, p. 168 (1980).

12. Cottrell, J.E., Gupta, B. \& Turndorf, H. Induced hypotension. Anesthesia and neurosurgery. Edited by Cottrell, J.E., and Turndorf, H. St. Louis, Mosby, p. 387 (1980).

13. Michenfelder, J.D., GronerT, G.A. \& RehDER, K. Neuroanesthesia. Anesthesiology 30 65 (1969).

14. Hagerdal, M., Harp, J.R., Nilsson, L. \& SIESJO, B.K. The effect of induced hypothermia upon oxygen consumption in the rat brain. $\mathrm{J}$. Neurochem. 24:311 (1975)

15. Albin, M.S., BabinsKi, M., Maroon, J.C. \& JANNETTA, P.J. Anesthetic management of posterio fossa surgery in the sitting position. Acta Anaesth. Scand. 20: 117 (1976).

16. Michenfelder, J.D., TERRY, H.R., DAw, E.F \& MilLER, R.H. Air embolism during neurosurgery - a new method of treatment. Anaesth. Analg. 45: 390 (1966)

17. Maroon, J.C., Goodman, J.M., Horner, T.G. \& CAMPBELl, R.L. Detection of minute venous air emboli with ultrasound. Surg. Gyne. Obstet. 127: 1236 (1968)

18. Marshall, B.M. Air embolism in neurosurgical anaesthesia: its diagnosis and treatment. Can. Anaesth. Soc. J. 12: 255 (1965).

19. Barro, ARLENE R. Survey and evaluation of approaches to physician performance measurement. Assoc. of American Medical Colleges [N.D.], Washington, D.C.

20. Cottrell, J.E., Rosustelli, A., Post, K. \& TURNDORF, H. Furosemide and mannitol induced changes in intracranial pressure and serum osmolality and electrolytes. Anesthesiology 47: $28(1977)$.

21. Guide to hospital accreditation 1977. Toronto Canadian Council on Hospital Accreditation, $p$. 20 (1977).

22. HaRdYMENT, A.F. Peer group analysis - a form of medical audit: its role in continuing medical education. Can. Med. Assoc. J., 104: p. 1104 (1971).

\section{RESUMÉ}

Les auteurs décrivent comment on peut parvenir à une évaluation formelle de l'anesthésie neurochirurgicale à partir d'une évaluation normative. Les critères applicables et leur signification clinique sont énumérés. Il faut retenir que les paramètres mentionnés par les auteurs ne devraient pas servir de critères pour l'évaluation de la qualité de l'exercice de 
l'anesthésie mais bien de sujets de discussions entre anesthésistes qui participent à une évaluation formelle de l'acte anesthésique particulièrement lorsque le nombre de cas ne permet pas l'analyse statistique des résultats cliniques et lorsque seule la discussion de cas particuliers ou de petits nombres de cas n'est possible. Il est suggéré comme d'autres l'ont déjà fait de perfectionner le mode d'évaluation formelle de la qualité de l'acte anesthésique de façon à lui permettre de devenir la forme d'enseignement médical continu la plus adaptée aux besoins du clinicien. 